Trab. Ling. Aplic., Campinas, 43 (2): 227-248, Jul./Dez. 2004

\title{
AVALIAÇÃO EM CONTEXTO DE GESTÃO DE QUALIDADE TOTAL: CONSTITUIÇÃO DO JOGO DISCURSIVO EM UMA REUNIÃO DE PROFESSORES ${ }^{1}$
}

\author{
MARIA DE FÁTIMA S. AMARANTE \\ (PUC/CAMPINAS)
}

\begin{abstract}
Teachers' discourse on evaluation is focused in the framework of a process of institutional quality management, an outcome of the neoliberal project that is pervading educational contexts. From a Discourse Analysis' perspective, the conditions for the production and the materiality of the discourse produced during a staff meeting are discussed in terms of the effects of the pervasiveness of neoliberal concepts, notions and principles on power-knowledge relationships.

Keywords: oral evaluation, discourse, quality management.
\end{abstract}

No campo educacional, o projeto neoliberal apresentou-se como meio de superação minimamente intervencionista da "crise da educação", que tem sido constantemente reinscrita e reescrita nas metanarrativas educacionais. Na perspectiva neoliberal, a crise da educação é diagnosticada a partir da constatação da inadequação da formação escolar para uma atuação eficiente, isto é, competitiva, no mercado global. Assim, o projeto neoliberal, que parte da premissa de que a educação, em condições ideais de desenvolvimento, deve responder e se ajustar às demandas e às exigências do mercado, constitui discursos educacionais em que a questão da qualidade é apologeticamente convertida em meta compartilhada, em palavra de ordem mobilizadora (Enguita,1994:98).

É neste contexto que se situam os resultados de pesquisa aqui apresentados, com base na perspectiva da análise de discurso, que considera a importância das condições de produção e da materialidade lingüística para o estudo dos efeitos de sentido produzidos.

\section{PROJETO NEOLIBERAL E CONSTITUIÇÃO DO DISCURSO EDUCACIONAL}

A centralidade do lema da qualidade é identificada, no projeto educacional neoliberal brasileiro, com a questão da avaliação, especialmente porque, nos anos oitenta, recrudescem

\footnotetext{
${ }^{1}$ Este trabalho reporta a capítulos de minha Tese de Doutorado, intitulada "Avaliação da Aprendizagem e Ideologia Neoliberal: A Excelência e o Avesso da Excelência”, apresentada ao IEL/ UNICAMP, em 1998. Inclui, no entanto, atualização de alguns dados e alterações no tocante à sua análise, fruto de reflexão posterior sobre o trabalho então elaborado.
} 
os discursos que apontam as altas taxas de evasão escolar, os maus resultados em comparação com outros países, a queda do nível, a crise da disciplina como ameaças à eficiência que garantiria a inserção do país no mercado global, isto é, à sua competitividade. A excelência, grau máximo da qualidade, passa, então, a ser a principal meta propagada pelo discurso oficial.

Na opinião de Gentili (1994:116),

a retórica conservadora da qualidade no campo educativo presume a dinâmica que chamaremos "duplo processo de transposição". A primeira dimensão deste processo remete ao mencionado deslocamento do problema da democratização ao da qualidade; a segunda, à transferência dos conteúdos que caracterizam a discussão sobre qualidade no campo produtivo-empresarial para o campo das políticas educacionais e para a análise dos processos pedagógicos.

Esse processo implicou que os critérios, baseados na lógica produtivista e mercantil, utilizados para a avaliação da qualidade no mundo dos negócios passassem a ser utilizados no âmbito educacional. Dessa forma, foram incorporadas às práticas pedagógicas estratégias derivadas de noções tayloristas, tais como o controle de qualidade e a organização do processo produtivo. Em conseqüência, em nosso entender, todo o processo educacional passou a se pautar pelos princípios da qualidade como prova e das provas da qualidade, pois uma das operações centrais do projeto neoliberal consiste em transformar questões políticas e sociais em questões técnicas. Assim, os problemas educacionais são tratados como técnicos, questões de eficácia/ eficiência na gerência e administração de recursos humanos e materiais, e de reforma de métodos de ensino e conteúdos curriculares inadequados.

Tal quadro político-educacional tem reflexos diretos no interior das instituições escolares e, em especial, nos discursos educacionais sobre a avaliação em que ela assume um papel estratégico, isto porque qualidade enquanto referencial axiológico já pressupõe avaliação. Assim, a avaliação assume caráter instrumental para a garantia da produtividade e da excelência; torna-se, em nosso entender, local privilegiado de ação, já que é a marca concreta da qualidade/falta de qualidade do produto educacional. Se acreditamos, como Enguita (op. cit.:95), que qualidade se transforma no eixo de um discurso fora do qual não é possível o diálogo, porque os interlocutores não se reconhecem como tais senão através de uma linguagem comum, somos forçados a reconhecer que os discursos educacionais irão tender a se concentrar cada vez mais na avaliação. ${ }^{2}$

Cabe apontar, então, que nos vemos constrangidos a pressupor que o ideário neoliberal irá encontrar, nas instituições de ensino superior de caráter privado, contexto favorável para a disseminação de seus conceitos, noções e princípios. Baseamos nossa pressuposição em três principais premissas derivadas da própria natureza dessas instituições: a) sua natureza privada, isto é, empresarial a posiciona no mundo dos negócios; b) sua função de formação de mão-de-obra especializada a posiciona na economia globalizada e na esfera de poder

${ }^{2}$ A Lei de Diretrizes e Bases da Educação Nacional, promulgada em dezembro de 1996, contém vários artigos acerca do tema. No caso da educação superior, cabe destacar a instituição do Exame Nacional de Cursos e, mais recentemente, do Exame Nacional de Desempenho Escolar provocaram a proliferação de discursos sobre avaliação nos mais diversos contextos sociais. 
diferencial e c) seu caráter produtivo, no que se refere tanto à produção de conhecimentos quanto à produção de indivíduos disciplinados, a posiciona no mundo do capital cultural ${ }^{3}$.

Baseando-nos na análise apresentada por Azambuja (1996) acerca do que ocorre no âmbito empresarial em geral, podemos afirmar que, na instituição educacional de cunho privado, são estabelecidas relações contratuais entre a escola/empresa e o aluno/cliente, entre a escola/empresa e o professor/empregado e entre a escola/empresa e o mercado de trabalho/cliente, que exigem a garantia da qualidade, ou, para sermos mais incisivos, que exigem a geração de confiança na qualidade.

A instituição escolar de cunho privado, inserida no mercado dos bens educacionais em que a concorrência pelo aluno/cliente e pelo mercado de trabalho/cliente ocorre tanto com suas iguais quanto com instituições de ensino público, enfrenta, por conseguinte, a tarefa de assegurar o aporte de recursos financeiros de que tem necessidade para se manter. Tais recursos só podem advir do faturamento da escola/empresa, o que depende, então, da venda de seus serviços educacionais (cursos) e de seus bens educacionais (alunos). Para isso, ela terá de atrair e manter clientes (alunos e mercado de trabalho), em um volume de negócios compatível com a dimensão da própria empresa. Essa tarefa pode se tornar extremamente difícil, a depender de quão numerosos, competentes e agressivos sejam seus competidores.

Do ponto de vista empresarial, a única fórmula segura para sobreviver e prosperar frente à concorrência é obter, ao longo do tempo, a contínua preferência dos clientes, ou seja, não perder clientes antigos e conquistar sempre clientes novos. Para isso, os produtos (serviços e bens) da empresa têm de satisfazer a esses clientes. E a escola/empresa só será competitiva se seus produtos forem mais satisfatórios que os de seus concorrentes, o que, em situações de grande competição, depende da atenção dispensada a ouvir a "voz" do cliente, interpretá-la e incorporá-la em seu discurso.

De modo a garantir a satisfação do cliente, então, estão associadas as interpretações de "qualidade planejada" (aquela idealizada, projetada, fruto do consenso entre empresa e cliente), "qualidade realizada" (aquela que foi efetivamente gerada, produzida) e "qualidade percebida" (aquela que o cliente captou, percebeu). Esta última é que consagrará ou não a escola/ empresa, pois representa, sempre, o julgamento da instituição pelos clientes que, na prática, validam ou não o produto ou serviço recebido.

De outra parte, a sobrevivência da escola/empresa depende também da satisfação de outros conjuntos de pessoas cujas vidas são influenciadas pela instituição, como, por exemplo, seus empregados, cuja insatisfação com os produtos e desempenho da escola/ empresa pode gerar dificuldades ao seu funcionamento normal e, dessa forma, comprometerlhe a sobrevivência. Em decorrência, mais do que treinar pessoas em rotinas de gerenciamento, operações e verificações, a proposta educacional/empresarial neoliberal

${ }^{3}$ Cabe deixar claro que, também nas instituições públicas de ensino superior, o ideário neoliberal irá encontrar condições para propagação, como bem o demonstram, por exemplo, a crescente inserção de tais instituições nos programas governamentais de avaliação institucional e a adoção de medidas que visam a garantir o bom desempenho de seus alunos nos Exames Nacionais de Cursos. Entretanto, entendemos que, nas instituições de caráter privado, em que o vínculo econômico direto com alunos e empregados é inerente à sua natureza, tais condições são inegavelmente mais propícias. 
deve ser assinalada como sendo a de desenvolver as potencialidades dos indivíduos para a geração de soluções de eventuais problemas ou melhorias na organização, pois a empresa/ escola deve estar em processo de contínuo aperfeiçoamento, de modo a assegurar a satisfação do aluno/cliente e do mercado de trabalho/cliente.

Um dos modos de desenvolver as potencialidades dos indivíduos é promover contínua oportunidade de compartilhamento de idéias e experiências, de forma a obter soluções consensuais de modo organizado e controlado. Isto é, na empresa/escola, as tradicionais reuniões de professores são transmutadas em círculos de qualidade, em que cabe a uma gerência participativa promover o consenso acerca de todos os detalhes do processo, sinal de eficiência e, portanto, de produtividade e competitividade. Assim, aos professores passa a caber, quase que exclusivamente, a responsabilidade pela excelência do aluno/produto e pela satisfação do aluno/cliente e do mercado de trabalho/cliente.

Em outras palavras, o discurso sobre avaliação produzido durante uma reunião de professores que é parte de um processo organizacional de gestão de qualidade instaurado no contexto educacional a partir de sua constituição pela ideologia neoliberal, passaria a ser constituído por uma nova configuração das relações interfuncionais. Estas passariam a se reger pelos princípios da gerência participativa e do círculo de qualidade, cujo funcionamento constrangeria quem pode ou não pode dizer, quando pode ou não pode dizer, o que pode e não pode ser dito, já que, do ponto de vista de sua macroestrutura, uma reunião de professores organizada em tais moldes se fundaria sobre o princípio da democracia heteronômica. Devemos nos remeter aqui a Lima (1980:47), que afirma:

O mundo atual, independentemente dos sistemas políticos adotados, vive, do ponto de vista das relações diretas entre indivíduos, em plena e total heteronomia. A heteronomia é o modelo de relacionamento entre os indivíduos, em que as regras são impostas 'de fora', isto é, não surgem da equilibração do próprio relacionamento. Ao contrário, supõe alguém, em nível superior, determinando as regras.

Portanto, examinar a constituição do discurso produzido por professores acerca da avaliação no interior das instituições de ensino superior, a partir da hipótese de que tais instituições poderiam (e deveriam) ser, por excelência, locais de resistência ao projeto neoliberal, foi o que nos moveu a tomar para análise a transcrição de uma reunião de professores (doravante P1, P2, P3, P4) de inglês de uma instituição privada de ensino superior, que foi gravada em áudio e transcrita, como um texto, na acepção da corrente teórica da análise do discurso que

o concebe como sendo o resultado concreto, opaco, mas revelador, de um processo discursivo ancorado em condições de produção marcadas sócio-ideologicamente, inscritas na historicidade de um momento e capazes de explicitar a manifestação lingüística e os efeitos de sentido que ela provoca (Coracini, 1993:4).

Assim, procedemos ao estudo da distribuição do poder e dos principais procedimentos argumentativos utilizados pelos interlocutores, de modo a verificar a ocorrência de discursos de resistência e/ou de adesão a princípios, noções e conceitos neoliberais. Isto porque, entendemos que, se as reuniões de professores passam, do ponto de vista de uma política 
de planejamento estratégico baseada em qualidade total, a ser encaradas institucionalmente como parte de um processo maior de organização dos processos de trabalho, as trocas enunciativas que aí ocorrem possivelmente se caracterizam por procedimentos que revelam a operação produtivo-restritiva determinada pelas formações ideológicas e pelas formações discursivas (na acepção que lhes empresta Foucault) em que o discurso educacional se inscreve.

\section{EXERCÍCIO DE PODER E HETERONOMIA}

O estabelecimento de uma pauta de discussões bem como a ordenação dos temas a serem discutidos, que, no caso da reunião sob análise, são feitas pelo coordenador de Departamento $(\mathrm{P} 1)$ devido às relações administrativo-pedagógicas hierarquicamente organizadas e reconhecidas no contexto institucional, são condições de produção para o jogo discursivo que aí se desenrola. Da mesma forma, o fato de P1 ser o gerenciador da reunião, devido à sua posição hierárquica superior e de, portanto, a ele caber distribuir a palavra de modo que o princípio democrático, ou seja, a distribuição do exercício de poder seja garantida, remete, também, à relação heteronômica. A função de P1 é a de organizar o jogo discursivo, de modo que potenciais conflitos resultantes da distribuição de poder sejam solucionados pelo consenso, isto é, a atuação gerencial de P1 na distribuição de turnos se configura, também, como condição de produção para as trocas enunciativas durante a reunião. Por conseguinte, as posições dos interlocutores - no caso da reunião de professores, evento que tem como objetivo a tomada de decisões de caráter administrativoacadêmico acerca do desenrolar do processo ensino e aprendizagem - são, por um lado, determinadas externamente, ou seja, são legitimadas pela própria hierarquia administrativa de cargos e funções estabelecida no interior da instituição. Deste ponto de vista, há de se considerar que os enunciados de P1 e P4, que ocupam cargos administrativos na instituição (coordenador de departamento e vice-diretor, respectivamente) são legitimados externamente, de forma diferenciada daqueles produzidos por P2, P3 e P5.

De outra parte, devemos indicar que todos os envolvidos são professores de inglês, ocupando, no quadro institucional, uma mesma posição e, por conseguinte, seus enunciados teriam o mesmo grau de legitimidade externamente constituída. No entanto, P1 e P4 também exercem funções administrativas e, portanto, ocupam duplo posicionamento institucional. Este duplo posicionamento de P1 e de P4, que constitui relações hierárquicas legislativamente determinadas, tem efeitos legitimadores para os seus enunciados que vêm se sobrepor àqueles propiciados pelo posicionamento que compartilham com os demais interlocutores. Já P2, tendo, no passado, ocupado cargos administrativos, também é posicionado duplamente, o que lhe garante maior espaço nas trocas enunciativas no decorrer da reunião.

Ademais, é importante salientar que também são constitutivas das posições que os interlocutores ocupam no interior do discurso as relações que se estabelecem entre eles com base no tempo de permanência de cada um deles na instituição. Isto porque o fato de, na instituição locus de nossa pesquisa, até muito recentemente, o critério utilizado para a atribuição de aulas aos professores ter sido o da antigüidade na casa determina grandemente 
o espaço institucional que cada professor ocupa. Dessa perspectiva, portanto, a antigüidade na instituição também se configura como índice de posicionamento dos sujeitos e contribui para constituir um quadro bastante estático das relações hierárquicas no interior da interação.

Finalmente, devemos apontar que o fato de a formação do quadro docente da instituição ter-se caracterizado por um processo endogênico tem efeitos no posicionamento dos interlocutores na interação. Assim é que a existência, no passado, de relações do tipo professor/aluno entre os interlocutores influi também nos enunciados por eles produzidos.

Por outro lado, tais posições são também determinadas internamente, isto é, pelas condições objetivas do próprio desenrolar das trocas enunciativas no decorrer da reunião, aquelas que são permeadas pelo desempenho de papéis que fazem circular o poder de tal forma que seu exercício, provisório, mas, certamente, hegemônico de um ponto de vista temporal, é determinado pela utilização de estratégias argumentativas que, em última instância, constituem a tentativa contínua de congelar a hierarquia de relações constituídas externamente. Assim, o conflito, a circularidade e a transitoriedade do poder, constituídos pelas e nas trocas enunciativas no texto em questão e nos textos que o constituem, produzem redes complexas de relações de poder.

Em suma, podemos afirmar que, no jogo discursivo que se desenrola durante a reunião dos professores, o dinamismo das relações hierárquicas, sua mobilidade e descontinuidade, no dizer de Foucault (1975/1987), constituem a especificidade da luta pelo exercício de poder que vem se materializar lingüisticamente na utilização de estratégias argumentativas que remetem a um apagamento de mobilidade e descontinuidade, criando efeitos ilusórios de unidade e equilíbrio na distribuição dos exercícios de poder.

\section{O JOGO DISCURSIVO NEOLIBERAL}

Partindo da premissa de que o discurso é constitutivamente heterogêneo, ou seja, de que todo discurso se constitui de uma dispersão de textos e, por conseguinte, de uma dispersão de sujeitos (conforme Orlandi e Guimarães, 1988:17) e, portanto, há de se ter presente que o discurso é um processo dialógico devemos considerar que sua heterogeneidade é um procedimento argumentativo. Assim, ao nos referirmos aos participantes dessa reunião como interlocutores, estamos adotando o ponto de vista de Ducrot (1987), segundo o qual o Locutor é a voz que, no discurso, toma a responsabilidade daquilo que é enunciado e o faz de seu posicionamento simultâneo de falante-ouvinte. Os efeitos argumentativos de seus enunciados são, assim, constituídos tanto pelas posições, social e institucionalmente reconhecidas, que ocupam em relação uns aos outros quanto pelo fato de que todo discurso nasce de outro discurso e reenvia a outro (Orlandi, 1986:26), ou seja, que as posições que os interlocutores ocupam na instituição bem como as que ocupam no interior do processo discursivo são condições de produção de seu discurso.

O reducionismo das discussões pedagógicas à questão da avaliação da aprendizagem se deve ao fato de que a questão do sucesso escolar (que, conforme iremos a seguir apontar, aflora na materialidade lingüística do discurso dos professores em seu pólo oposto, que é o fracasso escolar) tornou-se central a partir da constituição do discurso educacional pelos princípios da competitividade e da produtividade característicos da ideologia neoliberal, 
pois a avaliação passa a ocupar, no imaginário de administradores e professores, um outro espaço além daquele de estratégia pedagógica: passa a ser reconhecida como instrumento que garante a sobrevivência da própria escola e, conseqüentemente, dos profissionais da educação. Se, no ideário neoliberal, o sucesso ou fracasso do aluno é medida da competência ou incompetência da escola e dos professores, a avaliação passa a ocupar todo o espaço educacional. Isso porque, compondo uma formação ideológica em que a educação assume a feição de bem ou produto educacional e em que, portanto, as relações educacionais se regem pelas leis de mercado, isto é, pela lei da oferta e da procura e pela lei do custo e do benefício, a formação discursiva escolar encontra na visibilidade e na dizibilidade da avaliação a mais poderosa estratégia publicitária e política.

De nosso ponto de vista, à medida que o projeto hegemônico neoliberal ganha forças no interior da instituição, constituindo os sujeitos educacionais e seus discursos, multiplicamse os eventos discursivos e não-discursivos que dizem respeito à avaliação. Em outras palavras, o caráter axiológico das ações e dos discursos educacionais sobre avaliação se faz mais visível e dizível na instituição escolar, já que se passa a atribuir à avaliação um valor estratégico e tático positivo.

A análise do texto da reunião de professores nos permite observar que - apesar de, no decorrer da reunião, vários juízos de valor serem emitidos acerca dos aprendizes - a ocorrência desses enunciados não é percebida pelos interlocutores como eventos avaliativos. Nota-se, no Excerto 1, transcrito a seguir ${ }^{4}$, que, ao discutir as sugestões apresentadas por P1 quanto à utilização de determinados exercícios que visam ao ensino/aprendizagem da pronúncia em inglês, são emitidos juízos de valor acerca dos alunos que remetem às seguintes imagens: a) o aluno é coletividade, não sendo considerado em sua individualidade; b) o aluno não é capaz.

\section{Excerto 1}

P1- Eles não conseguem/não conseguem ter a noção de surdo e sonoro... assim se repetir... Pl- ((XXX)) Além dessas tem outras que a gente tinha visto. Eu tinha pensado em fazer. Aqui eles têm muito problema com humm [izi] ((easy)), [fórI] ((forty)), nos números, né?

P2- Ah, o [i] final o aluno não consegue distinguir. ((XXX)) Tem que falar mil vezes pra ele notar a diferença.

Através da utilização do pronome pessoal de terceira pessoa do singular ou do plural e, também, através do uso do artigo definido ( $\underline{\text { Eles }} \underline{\text { o }}$ aluno/ $\underline{\text { ele }})$, os aprendizes são tomados

\footnotetext{
${ }^{4}$ Estaremos utilizando os seguintes símbolos de transcrição:

$\mathrm{P}=$ professor

$\mathrm{A}=$ aluno

/ = fala entrecortada

[ ] = transcrição fonética

(( )) = comentários do pesquisador

$((\mathrm{XXX}))=$ seqüência incompreensível

$(\ldots)=$ omissão de trechos da fala

$\mathrm{X}=$ supressão de nome próprio
} 
como grupo, cuja identidade não é marcada pela diferença, mas revelada na determinação de sua indiferenciação. O aprendiz é, portanto, objeto, entidade a que uma história pessoal e social é negada, pois sua história é aquela de todos os demais aprendizes. Dessa forma, esse pensar padronizado sobre o aprendiz acaba por constituir elementos poderosos do imaginário nas significações dos professores e passa a produzir um certo determinismo apriorístico e fatalista em relação ao desempenho do aprendiz. A questão do fracasso escolar no nível do ensino superior (a exemplo do que ocorre nos níveis fundamental e médio) pode, então, ser enunciada como sendo derivada do baixo rendimento cognitivo dos aprendizes (Eles não conseguem/não conseguem ter a noção de surdo e sonoro) e, portanto, o problema pode ser enunciado como sendo de ordem curricular. Assim, as soluções são buscadas através de mudanças e adequações curriculares que envolvem, especialmente, a organização dos conteúdos mínimos, a redução e transformação de programas. Moldadas nos padrões da escola tradicional, cujo papel é a transmissão do saber sistematizado e socialmente acumulado, tais soluções baseiam-se na primazia do conteúdo sobre o sujeito. Soluções são também calcadas na primazia do método sobre o sujeito, que se identifica com os procedimentos behavioristas (pragmáticos/ positivistas), sempre na perspectiva de melhoria do desempenho e aumento da produtividade (Assim, se repetir...).

Qualquer que seja a perspectiva das soluções buscadas, professor e escola não afloram como elementos do insucesso escolar, que é sempre percebido no outro, o aluno. Instaurase, portanto, um processo em que a escola e o professor perdem a sua parte de responsabilidade sobre a aprendizagem, o que, de nosso ponto de vista, determina o reducionismo do processo pedagógico ao processo de avaliação e que se revela no exacerbamento do exercício de micropoderes pelo professor, no intuito de garantir melhor desempenho e maior produtividade. $\mathrm{O}$ discurso educacional sobre avaliação pode ser encarado, então, como um instrumento de conservação, de resistência ao exercício fluido do poder, à sua mobilidade e descontinuidade e as imagens que nele afloram e se fixam continuamente são as do aluno como tabula rasa e do professor como detentor do conhecimento e das decisões acerca do processo educacional. ${ }^{5}$ A priorização de processos mnemônicos de aprendizagem revela, por sua vez, a imagem do aluno como incapaz, o que exige que o professor simplifique e ordene no tempo e no espaço o conhecimento, exagere o modelo, repita-o, revelando uma política do afeto calcada no fato de que as potencialidades do aprendiz são subestimadas, conforme se pode observar no Excerto 2, a seguir, em enunciados tais como: Eu exagero, inclusive dá pra eles reconhecerem os sons .

\section{Excerto 2}

P3- Eu exagero.

P4- Demora um pouco.

P3-Inclusive, inclusive dá pra eles reconhecerem os sons.

\footnotetext{
${ }^{5}$ Devemos nos lembrar que, para Foucault (1976), a detenção do saber tenderia para o específico, onde o sujeito demarcaria o caráter revolucionário (produtivo) pelo domínio específico de um determinado saber, por sua competência técnica e científica. Assim, as relações pedagógicas e interpessoais nas salas de aulas determinam maior exercício de poder ao professor a partir da imagem socialmente construída e aceita, ou seja, universalizante, de que é ele quem detém o saber. Somente a ativação dos saberes locais, descontínuos, desqualificados e ainda não legitimados em nossa sociedade é que poderá, no entender de Foucault, constituir a luta contra o universal hegemônico, posição com a qual concordamos plenamente.
} 
Tal política do afeto, que, no excerto acima, naturaliza procedimentos pedagógicos calcados no exagero, é atualizada e legitimada, no excerto que se segue, através do recurso à exemplificação (Em português você não tem zê final. A não ser que você faça uma elisão, por exemplo, [azagwas]) combinada à narrativização (Daí eu mostrei pra eles que em português só existe quando há uma elisão, [azagwas], né?). Esses enunciados permitem, então, a prescrição final, materializada através da modalização deôntica (Tem de exagerar.).

\section{Excerto 3}

P3- Em português você não tem zê final. A não ser que você faça uma elisão, por exemplo, [azagwas] ((as águas)). Daí eu mostrei pra eles que em português só existe quando há uma elisão, [azagwas] ((as águas)), né? Agora, então, quando eles vão falar, por exemplo, "leaves" ((exagerando a pronúncia do morfema final)). Tem de exagerar.

A utilização de tais recursos propicia sentido de causa e efeito, que é uma estratégia altamente persuasiva. Valida-se, assim, o procedimento facilitador. A força da narrativização, que constrói o futuro com base na experiência passada, somada à força da exemplificação, que propicia tanto a afirmação do domínio do campo de conhecimento pelo professor quanto à afirmação da cientificidade de sua asserção, cria efeitos de sentido legitimadores que conduzem ao apoio do interlocutor.

Há de se salientar que se busca que o processo de tomada de decisão construído discursivamente acerca da boa economia dos investimentos seja um processo negociado coletivamente na batalha discursiva que se trava entre os professores (princípio do círculo de qualidade), mas gerenciado por P1 (princípio da gerência participativa) e que a boa economia dos investimentos está baseada na ordenação, gradação, e controle do conhecimento (princípio da gerência de processos).

Tanto o conhecimento quanto a ação do professor assumem, em conseqüência, caráter instrumental, finalista, em que os meios justificam os fins. O caráter "utilitarista" do conhecimento, então, torna-se o princípio básico de todo o processo educativo. Ademais, há de se notar que se trata aqui de buscar o lado formal da qualidade: é a forma que está em jogo. Em uma perspectiva mais ampla, uma vez que consideramos que o discurso educacional sobre avaliação é constituído por princípios e conceitos neoliberais, concordamos com Demo (1996:25), quando ele afirma que o neoliberalismo empurra para a competitividade e que a busca de competitividade realça o lado formal da qualidade, que é o manejo do conhecimento, considerado instrumento primordial das mudanças. Aponta para um tipo de habilidade fundado no domínio metodológico instrumental, ou seja, a manipulação dos meios.

Assim, a instrumentalidade das ações educativas a par da instrumentalidade do conhecimento são princípios neoliberais que visam a garantir a qualidade do produto/ aluno, de modo a torná-lo competitivo no mercado de trabalho. O perfil profissiográfico do professor de inglês como língua estrangeira que tem qualidade para competir no mercado de trabalho, por conseguinte, é determinado por sua habilidade em manipular os meios. Portanto, a instrumentalidade, enquanto estratégia de legitimação, propicia valor qualitativo de base econômica tanto aos professores que participam da interação sob análise, justificando 
a posição que detêm, quanto aos alunos que a irão adquirir e que são professores em formação.

O que se nota, então, é que a agência docente é calcada no julgamento apriorístico que, por sua vez, forma a base da argumentação prescritiva do professor. Já que cabe ao professor providenciar tratamento preventivo que, calcado no contraste, garanta o bom andamento do processo de ensino/ aprendizagem, a agência docente é prescritivoterapêutica. Assim, a agência docente se transmuta em agência médica. Como o bom médico que tudo já sabe sobre o paciente/aluno, pois faz generalizações com base em sua experiência, o professor é capaz de prever a doença/problema e prescrever tratamento/ ensino preventivo. Fica, pois, o aprendiz delimitado pelas fronteiras da posição que lhe é imputada - a de paciente -, e a agência é sempre consignada ao professor/ terapeuta. Mesmo as ações que caberiam ao aprendiz desempenhar aparecem, então, como campo de ação do professor. Examinemos o excerto que se segue, em que se pode observar a legitimação da agência prescritivo-terapêutica do professor (Tem que falar mil vezes pra ele notar a diferença.), através da narrativização e da exemplificação:

\section{Excerto 4}

P1- ((XXXl)) Além dessas tem outras que a gente tinha visto. Eu tinha pensado em fazer. Aqui eles têm muito problema com humm "easy", "forty", nos números, né?

P2- Ah, o éle final o aluno não consegue distinguir. ((trecho incompreensível)) Tem que falar mil vezes pra ele notar a diferença.

Quer-nos parecer que o que ocorre é a configuração de um quadro em que a agência docente não responde à diferença, ao particular e ao contexto vivido. Ela é uma agência rigidamente disciplinar, porque normativo-terapêutica, que restringe o significado e fixa a ação correta, pois o conhecimento não aflora aqui como valor estratégico, mas, antes, como valor prescritivo. Uma tal valoração do conhecimento aliada a uma abordagem do processo de aprendizagem de línguas que se fundamenta em demonstração e identificação por contraste pelo professor é altamente simplificadora, pois deixa ao aprendiz pouco espaço para a descoberta, delimitado que está a ser sujeito ativo somente na companhia e com a assistência do professor.

Podemos hipotetizar que o professor entende que assim deve proceder a partir de pressupostos que têm origem em uma concepção humanística de educação, ou antes, em uma concepção humanística que se transmuta em uma concepção "humanitária" e que propicia uma prática pedagógica assistencialista. Tal prática assistencialista é, a nosso ver, favorecida pela constituição neoliberal do discurso educacional sobre avaliação, que obriga o professor a tudo fazer para satisfazer o aluno/cliente de modo a mantê-lo como cliente. Da mesma forma, entendemos que a adoção de abordagens comunicativas para o ensino de línguas estrangeiras pode favorecer tal tipo de prática pedagógica, ao determinar para o professor o papel de facilitador da aprendizagem. Pignatelli (1994:139) argumenta, seguindo Foucault, que os professores exercem sua agência docente presos num complexo paradoxo, tipicamente moderno, entre sujeito cognoscente e objeto manipulado.

Cabe lembrar que, ao assumir o papel de facilitador da aprendizagem, o professor tem ampliado o seu exercício de poder, uma vez que a implementação de tecnologias de 
dominação é favorecida, pois a ele compete a tarefa de ordenar no tempo e no espaço os objetos a conhecer e os sujeitos do conhecimento. Temos, assim, um regime de discurso/ prática, de poder-saber, que permite que os professores afirmem que Eles (os alunos) não conseguem ter a noção de surdo/sonoro. Assim, se repetir..., que Eles têm dificuldade, que $O$ aluno não consegue distinguir, que Tem que falar mil vezes para ele notar a diferença e legitimem tais asserções como verdades. Portanto, é esse saber apriorístico sobre o aluno que constitui as relações de poder que se estabelecem na sala de aula.

De outra parte, essas relações de poder têm o saber como um de seus efeitos. Em outras palavras, é porque ao professor compete facilitar a aprendizagem, isto é, porque ele sabe acerca dos problemas de aprendizagem, ainda que virtuais, de seus alunos que lhe é possível estabelecer, manter e legitimar relações de poder que assujeitam o aluno, emprestando-lhe uma identidade coletiva, que, em última instância, favorece a produção de indivíduos normalizados, a partir de diagnósticos apriorísticos, tratamentos de prevenção e recuperação constituídos por esse poder/saber que constrói as identidades dos aprendizes como incapazes. Entretanto, é necessário ter em mente que, se tais tecnologias de dominação classificam e objetificam os indivíduos, esses indivíduos também constroem suas identidades, na medida em que tais classificações e objetificações são adotadas e aceitas por eles (Foucault, 1975).

Podemos afirmar, então, que, na reunião de professores que estamos analisando, a avaliação é uma questão política que é transmutada em questão técnica ou, melhor dizendo, à questão política da avaliação são apresentadas soluções técnicas que implicam alocação de tempo e espaço, especificação de procedimentos, consignação de resultado em expressão matemática. Observemos o excerto seguinte:

\section{Excerto 5}

P1- (...) E então o período de avaliação não seria/ então o período de avaliação, as moduladas não saíram lá no horário publicado. É uma experiência que está se fazendo para ver, porque se parte da premissa de que nas moduladas você tem mais chance de fazer avaliação contínua e tem menos alunos, conhece mais os alunos e poder avaliar, usar outras formas de avaliação. Mas eu pessoalmente acho que a gente deve marcar um dia e fazer as entrevistas.

P3- Dois dias.

P1- Dois dias.

P2- Dois dias.

P4- O professor X ((referindo-se ao diretor)) disse que isso seria opção de cada professor.

Como podemos observar, no que diz respeito à alocação no tempo, é contraposta a avaliação pontual, materializada em período de avaliação, em marcar um dia, à avaliação contínua. Cabe notar que P1, porque tem duplo posicionamento na instituição como administrador e como professor, apesar de se ver obrigado a justificar os procedimentos administrativos em favor da avaliação contínua (a não inclusão das disciplinas moduladas, isto é, práticas, no horário de provas) a eles se opõe, através da adversatividade: Mas eu pessoalmente acho ... Observa-se, aqui, que P1 se enuncia como sujeito dividido, separando a sua posição de administrador da sua posição de professor. É interessante notar, então, a 
contraposição no enunciado entre o uso da indeterminação, que permite a P1 não se colocar como sujeito enunciador (Porque se parte da premissa...) e o uso da modalização propiciada pelo verbo opinativo (acho) combinada ao expletivo (pessoalmente), de caráter reiterativo (eu pessoalmente), que permite a P1 explicitar-se como sujeito responsável pelo seu dizer e reafirmar-se como tal. Apresentando sua opinião como individual, P1 utiliza um argumento por autoridade, que traz à tona o seu duplo posicionamento: o que diz, então, é autorizado tanto por sua posição de administrador discordante, quanto por sua posição de professor experiente. $\mathrm{O}$ fato de $\mathrm{P} 1$, enquanto administrador, discordar do procedimento administrativo empresta grande força argumentativa a seu enunciado, pois ele se coloca como indivíduo com opiniões próprias.

Além disso, conforme podemos observar no excerto seguinte, ao buscar o apoio de seus interlocutores através do apelo ao consenso, materializado lingüisticamente em $a$ gente deve ter uma, uma unidade nisso, P1 cria um símbolo de unidade que tem forte efeito argumentativo, pois remete a uma identidade coletiva (a gente), contrapondo exclusão (você concentrou a sua avaliação.../ avaliação que você fez.) e inclusão (todos devem fazer mais ou menos da mesma forma). P1, portanto, materializa, em seu enunciado, a falta de unidade do grupo de administradores ao manifestar a sua discordância e, ao mesmo tempo, gera o consenso, a unidade, ao afirmar o seu pertencimento ao grupo de professores.

\section{Excerto 6}

Pl- Então como é que vai ficar resolvida a questão da avaliação? P4, eu acho que a gente deve ter uma, uma unidade nisso porque depois/

P2- É. Senão é "Por que eu não tive isso?"

P3- Eu acho que deve marcar uma data e fazer prova normal.

Pl- dá diferença de nota. Eu me lembro que no ano passado você concentrou de modo diferente a sua avaliação então as notas foram mais altas pelo tipo de avaliação que vocêfez.

P4- Pelo tipo de avaliação que eu fiz no primeiro semestre.

P1- Isto dá problema em relação ao final do ano, do aluno passar ou não. Como é que a gente resolve isso, não é? No sentido de que todos devem fazer mais ou menos da mesma forma.

P4- Agora se todos devem fazer mais ou menos da mesma forma, nós vamos entrar num acordo sobre como é que a avaliação vai ser conduzida.

P2- A avaliação o quê?

P4-Se ela vai ser gravada e você vai marcar todos os erros e depois você vai dar nota; se você vai dar nota direto depois da avaliação, usando critério, não usando critério, que critério vai ser usado. Quer dizer, isto tem de ser resolvido.

P1- Usando aquelas faixas. Eu realmente gosto das faixas, eu acho que elas me esclarecem, me dão certeza, me dão segurança e quando eu chamo o aluno depois da avaliação, eu faço entrevista com cada um. A classe não perde tempo não porque daí eu sempre dou uma atividade livre, enquanto eles estão fazendo a atividade livre eu vou chamando um por um e vou mostrando a ficha, esta ficha aqui, com os erros e eles vão vendo. 
Diferente foi, no entanto, a posição assumida por P4 que também tem duplo posicionamento. Na batalha argumentativa que se travou no Excerto 5, P4 assumiu a posição de administrador e reafirmou o seu pertencimento àquele grupo. Além disso, P4 argumentou em favor da individualização em oposição à unidade argumentada por P1. Recorrendo ao argumento por autoridade, trazendo à materialidade do discurso a voz da autoridade hierarquicamente superior através do discurso relatado, (O professor X ((referindo-se ao diretor)) disse que), $\mathrm{P} 4$ buscou apoio através do apelo à autonomia (isso seria opção de cada professor), contrapondo-a ao consenso proposto por P1 (a gente deve marcar um dia e fazer as entrevistas). Assim, o governo de outros foi deslegitimado e o autogoverno foi legitimado por P4, a partir dos bons propósitos de liberdade individual no Excerto 5, enquanto que o governo de outros é legitimado por P1 e por P2, nos Excertos 6 e 7, a partir de seus efeitos de liberdade democrática, que é garantida pela negociação que leva ao consenso. A questão da avaliação, da perspectiva do processo de tomada de decisões, aparece, portanto, como uma questão de governo. Governo de si e governo de outros, como se pode observar no excerto transcrito a seguir:

\section{Excerto 7}

P2- Eu acho que se a gente, que se um fizer e outro não fizer, eu acho que fica ruim. Eu acho que a gente deveria entrar num acordo.

A instituição representada por P4 no Excerto 5 parece propor menos governo - um dos princípios neoliberais - quando acena com a possibilidade de decisões individuais. Entretanto, ao propor e argumentar em favor da avaliação contínua, P4 acaba por configurar um quadro de mais governo, em que as ações de outros (professores e alunos) estarão sob permanente observação e o resultado de tal observação irá transformar a experiência de si, isto é, o modo como o ser humano se observa, decifra-se, interpreta-se, julga-se, narra-se e se domina. Os atores educacionais (professores e alunos) estarão, então, submetidos a um processo de constante visibilização e, em decorrência, de constante subjetivação, pois a avaliação contínua, enquanto dispositivo educacional irá constituir e mediar relações determinadas da pessoa consigo mesma e com os outros, configurando-se, a um só tempo, como tecnologia de dominação e tecnologia do eu, como se pode depreender dos seguintes enunciados: Se ela vai ser gravada e você vai marcar todos os erros e depois você vai dar nota; se você vai dar nota direto depois da avaliação, usando critério, não usando critério, que critério vai ser usado. Quer dizer, isto tem de ser resolvido. Com isso queremos afirmar que a avaliação educacional, antes de se apresentar como um mecanismo pedagógico, configura-se como um mecanismo institucional de caráter normativo-jurídico, através do qual são avaliados tanto aprendizes quanto professores. Vejamos como isso se materializa nos enunciados dos professores:

\section{Excerto 8}

P3- Mas aí dá uma nota só no final.

P4- Dá uma nota agora.

P2- Eu acho que a gente, se a gentel

P3-Agora eu não teria condições de dar uma nota para todo mundo. 
P1-Agora P4, se um não quiserl

P2- Eu acho que se a gente, que se um fizer e outro não fizer, eu acho que fica ruim. Eu acho que a gente deveria entrar num acordo.

P1- Eu acho.

P5- Eu não tenho condições de dar nota para ninguém por enquanto.

P3-Alguns até posso, mas tem muita gente que eu não posso.

P5- Tem uns quel os piores é fácil.

Para a instituição, de que P4 é a voz, o sinal de que os professores estão cumprindo as suas obrigações é a atribuição de um valor numericamente expresso ao desempenho do aluno, em momentos por ela estabelecidos (Dá uma nota agora). O vínculo empresa/ empregado o obriga a atribuir notas e é isso que constitui o professor enquanto profissional pertencente à instituição. Assim, também para o professor, a nota é a materialização do ato de avaliar. Essa obrigação, constituinte do professor, aciona processos de confissão, como se pode observar nos enunciados de P3 (Agora eu não teria condições de dar uma nota para todo mundo./ Alguns até posso, mas tem muita gente que eu não posso.) e de P5 (Eu não tenho condições de dar nota para ninguém por enquanto; Tem uns quel os piores é fácil). Dessa perspectiva, podemos considerar que o vínculo jurídico-empresarial entre a instituição e o professor estabelece relações de poder que obrigam o professor, a um só tempo, a tornar visível sua ação avaliativa e a, nelas ou em sua ausência, ver-se refletido. Obriga o professor a falar de sua ação avaliativa e de si próprio em relação a ela. E, a partir de operações que se materializam em atas de resultados de verificação de aprendizagem, em reuniões pedagógicas, em portarias e documentos diversos, fabrica sujeitos obedientes.

Larrosa (1994:79) aponta que

O poder, para afetar, traz à luz, fala e obriga a falar, julga. O ver, o dizer, e o julgar são, desse ponto de vista, parte das operações de constituição do que é afetado. As máquinas óticas, os regimes discursivos e os padrões jurídicos são inseparáveis dos procedimentos de fabricação de sujeitos obedientes à lei, normais e normalizados, atentos a si mesmos.

A instituição, em sua relação jurídico-empresarial com os professores, ao obrigá-los à confissão, transforma-os em sujeitos obedientes em dois sentidos: estão sujeitos à lei e sujeitados à sua própria identidade. Porque são sujeitos submetidos pela instituição e por si próprios a operações de visibilidade, de enunciação e de juízo, é que os professores, de modo a preservarem sua auto-imagem, ao confessarem a sua impossibilidade de cumprir a obrigação que lhes é exigida por P4 (Dá uma nota agora), enunciam tal impossibilidade

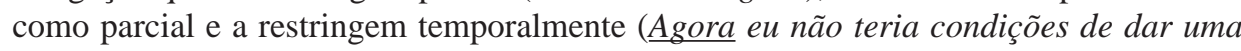
nota para todo mundo.; Eu não tenho condições de dar nota para ninguém por enquanto; Alguns até posso, mas tem muita gente que eu não posso; Tem uns quel Os piores é fácil.). Ademais, os professores colocam a impossibilidade de tornarem visível sua ação avaliativa como determinada de fora: não têm condições de cumprir a obrigação que lhe é exigida, o que os exime de culpa.

Por conseguinte, a avaliação contínua, enquanto forma exacerbada do mecanismo pedagógico da avaliação, por colocar em ação procedimentos óticos, discursivos e jurídicos 
de subjetivação, somente pode ser entendida como inseparável de operações de poder e submissão (Foucault, 1976), fazendo parte, ao mesmo tempo, das tecnologias de dominação e das tecnologias do eu que a instituição/empresa e os professores/empregados utilizam para garantir a governamentalidade em seus diferentes níveis de atuação.

A avaliação contínua, mecanismo que permite a constante visibilização de um domínio constituído por valores e normas como o contexto escolar, em que as distinções axiológicas que o estruturam são derivadas da distinção básica entre bom e mau, exacerba os efeitos de produção de identidade. Os indivíduos são agrupados e classificados em pólos opostos: aqueles a quem o professor pode dar uma nota no momento e aqueles a quem o professor não tem condições de dar uma nota por enquanto. O enunciado de P5 (Tem uns que/Os piores é fácil.) expressa claramente que tal agrupamento é feito com base na distinção entre bom e mau, que, no contexto escolar em que a avaliação pela norma predomina, converte-se na distinção entre melhores e piores. Tal asserção nos leva a considerar que separar o joio do trigo é considerada tarefa fácil, pois os piores se marcam pela falta, pelo desvio, pelo erro. Na cultura escolar da avaliação em que o professor está sempre em busca do erro, da dificuldade, do problema, a avaliação contínua surge como um potencializador de naturalização de juízos de valor que transitam na negatividade. $\mathrm{O}$ discurso educacional da avaliação produzido pelos professores é o discurso do avesso da excelência.

Entendemos que isso é possível devido ao fato de que a avaliação contínua não se materializa lingüisticamente como questão política no que se refere aos aprendizes, pois está em foco somente a qualidade formal ou, antes, a sua falta. Não se materializa na interação sob análise a qualidade política que se refere a fins e valores, ao ser humano como referência central, em particular para os compromissos éticos de uma história marcada pelo mínimo possível de exclusão (Demo, 1996:26).

Entretanto, a avaliação contínua materializa-se como questão política no que se refere aos professores, pois aflora, então, a questão do consenso, isto é, é necessário que todos se incluam em um mesmo processo, busquem os mesmos fins e valores. Visa-se ao estabelecimento de um compromisso ético que não exclua nenhum dos interlocutores; busca-se a qualidade política do processo. Cabe apontar, no entanto, que, mesmo nesse caso, a avaliação contínua se transmuta em questão técnica, pois se materializa no discurso como qualidade formal do processo de gestão organizacional, o que indica a sua constituição pela ideologia neoliberal. Esse processo de gestão organizacional inclui a diversificação de estratégias pontuais, a distribuição espacial dos eventos de avaliação, a distribuição temporal dos eventos, a documentação normalizadora e o silêncio acerca da avaliação. Vejamos o excerto abaixo:

\section{Excerto 9}

P4- E se, ao invés da gente fazer a entrevista oral, a gente fizer algumas coisas especiais para avaliação, em vez da entrevista?

P1- Por exemplo?

P3- O que eu posso él

P4- Um exercício no laboratório para nota, recolhendo; alguma apresentação em classe. 
AMARANTE - Avaliação em contexto de gestão...

Pode-se observar que P4, dando continuidade ao jogo discursivo, busca estabelecer uma relação dialética com seus interlocutores, premido pelo apelo ao consenso do enunciado de P2, no Excerto 8, em Eu acho que a gente deveria entrar num acordo. Utilizando-se da oração condicional, P4, ao mesmo tempo em que coloca em questão o procedimento tradicionalmente adotado para a avaliação da aprendizagem, introduz sua proposta como hipótese, apresentando-a, através da seleção semântica, na dualidade do geral/específico, materializado em coisas especiais. A força da argumentação de P4 reside, portanto, na incerteza e, podemos afirmar, foi constituída discursivamente pelo apelo ao consenso, anteriormente enunciado por P2. Assim, P4 obriga os interlocutores ao estabelecimento do diálogo, pois à possibilidade, veiculada pela utilização do modo condicional, somam-se a dúvida e a relevância, materializadas na generalização e na ênfase da seleção vocabular. O interlocutor se vê obrigado a entrar no jogo discursivo para, através da superação característica da dialética, chegar à verdade consensual.

Entretanto, há de se notar que a questão da avaliação é apresentada por P4 como uma questão de forma porque remete ao tipo de procedimento a ser adotado (entrevista oral contraposta a exercício para nota, recolhendo/ apresentação) e à distribuição espacial dos eventos (laboratório contraposto a em classe). Já a questão política, isto é, a questão de seus fins e valores, é colocada em segundo plano, quando não é inteiramente silenciada. No excerto a seguir, encontramos evidência confirmatória. A questão política (para avaliar pronúncia contraposto a para avaliar compreensão oral) se esboça, a partir da questão técnica da distribuição espacial dos eventos de avaliação:

\section{Excerto 10}

P2- no laboratório eu não acho que é natural a avaliação do laboratório. A avaliação do laboratório é só para avaliar pronúncia. Agora para avaliarl

P3-Mas vocêl

P1- Mas pode servirl

P4- Para compreensão oral.

P2- Mas só compreensão. E a avaliação mesmo?

Pl- Não, não. Você faria no laboratório a compreensão, depois você teria de fazer alguma complementação em classe.

P2- Aí, eu concordo.

Pl- Uma apresentação oral.

A questão política é imediatamente transmutada em questão técnica, que se apresenta sob a forma de argumentos em favor de procedimentos (utilização de exercícios e conteúdos mais fáceis e diversificados) e de recursos (alocação espacial e temporal diversificadas, utilização de equipamentos) que possibilitem superar a dificuldade de entendimento do aluno que o estabelecimento de uma política do afeto, outra estratégia da ideologia neoliberal, constitui como incapaz.

\section{Excerto 11}

P2- porque eles têm dificuldade ainda. Eles não estão acostumados. Nas primeiras aulas a gente não teve, não deu, não conseguiu fazer as lições do livro porque eles não tinham. 
As primeiras duas, três semanas. Então a gente começou faz pouco tempo que a gente começou com o material de laboratório. Então eles têm dificuldade de entender. Os meus, na maioria têm ainda dificuldade de entender. $((\mathrm{XXX}))$ Eles precisam se adaptar ao laboratório.

P4- E se a atividade de compreensão for feita na sala de aula em vez do laboratório?

P2- Você diz se a gente levar o gravador para a sala de aula?

P3- Eu tenho feito vários "roleplays" que eles tinham de fazer para nota.

P2- Eu tenho feito isso também, para nota.

P4- Mas aí é produção, né?

P3- É, é uma reprodução.

P4- E a nota de compreensão?

P3- Sim , mas eu acho que na produção que um faz vai envolver a compreensão do outro.

P2- Bom aí se você está pensando em termos de compreensão.

P1- Não, não, eu acho que valia a pena, a gente vem fazendo estes "listenings" extras do "In Touch".

P3- Tem um que eu não usei ainda, e acho que não vou usar. Não vai dar tempo.

P1- Uma idéia seria usar um deste tipo de "listening", por exemplo, que checasse compreensão de números, aquela "personal information" lá que vocês estão vendo, "spelling", né?

P2- Eu acho que a gente poderia. Eu não cheguei/

P1- A gente poderia montar uns programas.

P4- Eu não acho que deveria ser na mesma aula não. Eu acho que deveria fazer, por exemplo, numa aula você faz um de "spelling", na outra você faz um de números, de modo que fique diluído. Para não caracterizar que seja um dia de prova.

A questão política da avaliação é definitivamente transmutada em questão técnica quando se observa que os fins da avaliação se reduzem a um só objetivo: a nota (Eu tenho feito vários "roleplays" que eles tinham de fazer para nota; Eu tenho feito isso também, para nota), isto é, a marca que distingue sabedores de não sabedores. Vejamos o seguinte excerto:

\section{Excerto 12}

P3- De qualquer modo vai ser um dia que a gente vai fazer um exercício que a gente vai recolher para nota.

P5- A gente pode ir até avisando que nas próximas semanas nós teremos muitas atividades para a nota. Que ele estude, que ele se dedique.

Note-se que, também nesse excerto, P3 e P5, utilizando a adverbialização final (para nota), materializam lingüisticamente uma concepção redutora dos fins da avaliação. Observe-se, ainda, que a utilização da adverbialização modal por P3 (De qualquer modo) serve a enfatizar tal concepção. Já P5, ao emprestar sentido de concessão ao seu enunciado através do uso do modalizador de possibilidade (pode) aliado ao operador argumentativo até que, no excerto supracitado, indica concessão, aponta para o recrudescimento da política de afeto em relação ao aluno constituído como incapaz e que, portanto, deve ser instruído 
AMARANTE - Avaliação em contexto de gestão...

sobre a necessidade de estudo e dedicação para obtenção da nota. No excerto seguinte, a avaliação também é reduzida a uma questão de gestão dos processos de produção:

\section{Excerto 13}

P1-Atividades para avaliar o que ele conseguiu aprender até agora.

P5- É.

P3- Agora avaliação, compreensão oral gente isto leva tempo para eles aprenderem.

P5- Sem data marcada.

P3- Eles ainda não puseram a mão, agora esta avaliação de compreensão oral, que tempo eles têm de compreensão oral.

P2- Também a gente poderia

P4- Não precisa falar isso.

P5- Não?

P4- Eu acho que a gente não deve falar. A gente deve fazer o exercício e verificar como é que vai.

P3- Mas não tem que dar uma nota.

P1- Eu tenho feito isso com a fonética, sabe?

P4-Mas é um exercício só que vai recolher. É um exercício entre dez.

Pl- Eu tenho feito isso no segundo ano e no terceiro com as aulas de fonética. Tenho dado aos poucos e eu queria saber como eles estavam.

P3- $((X X X))$ entregar o papel quase vazio.

P4- Você não recolheu nenhum ainda?

P3- Ainda não porque eu estou sentindo que se eu fizer isso eles vão ficar desmotivados.

P2- Eu também acho isso.

P4- Eu recolhi e não houve este problema.

P3- E como é que eles foram?

P4-Eles foram muito mal, não entenderam nada e pediram a reação deles foi pedir que eu toque mais na sala de aula também.

P3- Mas sem saber que valia nota para avaliação?

P5-Sem saber. Eu já combinei com eles.

P4-Eles sabem que tudo que acontece na sala de aula é objeto de avaliação.

A entrevista oral, tomada como símbolo da avaliação pontual, aparece em contraposição a: algumas coisas especiais para avaliação; um exercício no laboratório, recolhendo; alguma apresentação em classe; uma apresentação oral; "roleplays"; "listenings" extras, muitas atividades para nota. Assim, a avaliação contínua, constante olhar valorativo, ou melhor, multiplicação de olhares valorativos, constituída pelo princípio neoliberal da qualidade total que, calcada na competitividade, propicia, no contexto educacional, a transmutação do bem cultural em bem de mercado e constitui sistemas de submissão e de dominação. Esses sistemas, por sua vez, constituem o lugar dos sujeitos bem como os sistemas de reconhecimento e autoconhecimento, que reafirmam tal lugar.

Cabe, então, observar que, enquanto sistema de submissão e dominação, a avaliação contínua pressupõe o silenciamento do professor acerca da avaliação, que é materializado na ausência de alocação temporal: sem data marcada e que propicia a multiplicação de 
seus efeitos disciplinadores: Eles sabem que tudo que acontece na sala de aula é objeto de avaliação, remetendo-nos à nossa afirmação anterior acerca da concepção redutora do processo de ensino/ aprendizagem à avaliação.

Assim, podemos encarar a avaliação contínua como um procedimento de gestão organizacional, que consolida a hierarquia institucional, demarcando seus limites e determinando pertencimentos. De fato, o que ocorre é que a aplicação dos princípios de gestão empresarial no contexto escolar sofre, no locus de nossa pesquisa, uma distorção. Na gestão empresarial da qualidade, dois tipos de avaliação são propostos: a avaliação de processos e a avaliação do produto. Na instituição escolar em que, tradicionalmente, vemse avaliando o produto, a inserção de práticas de avaliação contínua, ao invés de se reverter em práticas de avaliação de processos, vem-se configurando na multiplicação das estratégias, dos momentos e dos locais de avaliação do produto, como se pode observar no excerto acima. É necessário salientar que, sendo a reunião de professores uma estratégia administrativa de gestão dos processos de trabalho, calcada na gerência participativa e no círculo de qualidade, o fato de que as trocas enunciativas que ocorrem durante a interação também remetam a processos de organização é indicativo da constituição do discurso dos professores por estratégias neoliberais de gestão da qualidade. No entanto, é no que diz respeito à adoção de uma política do afeto e do sentimento que está intrinsecamente ligada à manutenção do cliente-aluno que, parece-nos, as trocas enunciativas analisadas revelam a constituição do discurso educacional sobre avaliação produzido por professores pela ideologia neoliberal, pois todo o processo avaliativo passa a visar à manutenção dos clientesalunos e, nesse contexto, o duplo posicionamento de $\mathrm{P} 4$, enquanto administrador e professor, é determinante, pois é ele que representa a empresa/instituição. Observe-se o excerto seguinte:

\section{Excerto 14}

P4- Nós temos tido resultados muito ruins nas primeiras provas e estamos assustando muito. Dos alunos que trancaram matrícula até agora sete disseram que estavam trancando matrícula por causa de inglês e não houve como convencer de que eles iam acabar aprendendo. Nós estamos com/ No ano passado, a maioria do pessoal que saiu deixou depoimento que era/você ((dirigindo-se a Pl)) estava até na reunião/ que era o inglês que causava mais a evasão que o português. A gente sempre achou que era o contrário, né?

Pl- A gente tinha a idéia, eu tinha a idéia que era o contrário. Pelo menos sempre acheil

P5- Três alunos já vieram me dizer que iam desistir. Agora como eu tenho mantido a aula metade em inglês, metade em português, que ele está sentindo melhor e que vai ficar.

P4 - É um problemal

P5- Eu achei importantel

P4- Eu acho que eles têm um monte de prova. Se inglês já é causa de desistência, se a gente faz uma prova dessas de entrevista oral em que ele vai ficar nervoso e eles estão sem saber como estudar e a gente sabe disso.

P3-É. 
A argumentação de P4 - que recorre à narrativização e estabelece uma relação de causa e efeito entre avaliação e evasão -, explicita, já no final da reunião, a ameaça que a avaliação representa para a manutenção dos clientes-alunos (Se inglês já é causa de desistência, se a gente faz uma prova dessas de entrevista oral em que ele vai ficar nervoso e eles estão sem saber como estudar e a gente sabe disso.). Assim, a argumentação de P4 ganha força, sustentando-se na premissa de que é preciso cuidar para que o cliente permaneça na instituição e esses cuidados remetem a uma imagem do aluno-cliente como frágil e desorientado. É essa argumentação de P4 que, finalmente, conduz ao consenso almejado: a coexistência da entrevista oral com outras formas de avaliação, como se pode observar a seguir:

\section{Excerto 15}

P1- Então com relação à avaliaçãoleu acho que da avaliação/ É... eu acho que vale a pena então estar se lembrando da compreensão, testar a compreensão e enfatizar a compreensão. É... e testar informalmente, né? Mas recolher pra ter um documento, né? Fazer essas entrevistas, já estar gravando alguma coisa, pra eles irem se acostumando com o gravador. E depois as entrevistas de junho a gente faz com gravação, né? E vai explicando, vai falando com eles agora a gente vai ter gravação, porque é bom/

P4- Eles vão acostumando, né?

P1- É um documento. O gravador é bom pro professor e pro aluno. Eu acho que nós não vamos ter problema.

Nota-se, então, a introdução de um novo elemento, o registro de qualidade (Mas recolher pra ter um documento, né?/ a gente vai ter gravação, porque é bom/ é um documento.) A documentação da avaliação é apresentada no enunciado de P1 como uma necessidade. Por um lado, a documentação é a prova de que o professor desincumbiu-se da tarefa de avaliar que lhe cabe institucionalmente. Por outro lado, é a arma de que o professor pode dispor para evitar que à sua sentença se encadeiem enunciados que recusem tal sentença como verdade. Mas isso é silenciado no discurso educacional sobre avaliação e o que se apresenta é uma estratégia de convencimento publicitário que apresenta a documentação como sendo benéfica a todos: professores e alunos.

\section{CONSIDERAÇÕES FINAIS}

A análise do discurso dos professores acerca da avaliação demonstra que é estabelecido um regime de verdade em que a avaliação, procedimento técnico, tem como ponto de partida uma imagem apriorística e, portanto, a-histórica do aluno como incapaz, imagem essa que é legitimada nos enunciados dos professores através de procedimentos de generalização, naturalização, reificação, modalização e indeterminação. Neste discurso, o fato de o aluno se tornar o centro do fracasso escolar configura um quadro em que todo o processo de ensino/aprendizagem é reduzido ao processo de avaliação, que se torna o único fim para o qual todos os esforços se voltam, na busca de soluções que garantam a 
manutenção do aluno/cliente satisfeito. Observa-se a instauração de uma política de afeto, constituindo a avaliação como uma série de procedimentos organizacionais que compreendem a diversificação dos instrumentos de avaliação, a distribuição espacial dos eventos de avaliação, a distribuição temporal desses eventos, a documentação normalizadora e o silêncio acerca da avaliação, que é, assim, um mecanismo disciplinar, cujo ponto de chegada é o ato jurídico-administrativo da atribuição da nota e seu registro. Uma política do afeto que, por um lado, revela uma estratégia neoliberal de transmutar questões políticas em questões técnicas e, por outro lado, revela a ilusão do princípio neoliberal do estado mínimo.

Neste discurso, o mecanismo pedagógico da avaliação é transmutado em mecanismo normalizador dos atores educacionais e de suas ações, tornando-se uma questão de governamentalidade. Para os professores/ empregados, trata-se de uma questão de autogoverno, de modo a cumprirem a tarefa institucionalmente estabelecida nos limites determinados pela empresa/escola, e questão de governo de outros, de forma a garantirem a manutenção do cliente-satisfeito, de se evitar a evasão, através da implementação de soluções técnicas que são legitimadas como minimizadoras do caráter proscritivo da avaliação. Para os professores que têm duplo posicionamento institucional, questão também de governo de seus pares, de forma a obter o consenso em torno de noções e estratégias que a empresa/escola quer legitimar.

O discurso dos professores aqui examinado não revela indícios de resistência ao projeto educacional neoliberal. Ao contrário, fortalece-o, ao contrapor à excelência idealizada a realidade de seu avesso, ao transitar sempre no pólo negativo da falta, da ausência, da diferença, que a agência docente, de caráter preditivo-prescritivo-terapêutico, deve e irá suprir, através de soluções eminentemente técnicas, pois a um aluno sem história, ou seja, sem a dimensão política de seu valor, só cabe uma avaliação "objetiva”, "organizada", "documentada": ao objeto-aluno corresponde outro objeto: o documento.

\section{REFERÊNCIAS BIBLIOGRÁFICAS}

CORACINI, M. J. R. F. (1993). Le Discours Politique Brésilien Contemporain: Un Exemple d'Hétérogénéité. Cahiers de Recherche du GRAL- Groupe de Recherche sur L'Amerique Latine. Université de Montréal: $51 \mathrm{p}$.

DEMO, P. (1996). Avaliação sob o Olhar Propedêutico. Campinas, SP: Papirus.

DUCROT, O. (1984). O Dizer e o Dito. Campinas, SP: Pontes, 1987. Versão Original.

ENGUITA, M.F. (1994). O Discurso da Qualidade e a Qualidade do Discurso. Em: Gentili, P.A.A. \& Silva, T.T. (orgs.) Neoliberalismo, Qualidade Total e Educação - Visões Críticas. Petrópolis, RJ: Vozes: p. 93-110.

FOUCAULT, M. (1975). Vigiar e Punir - Nascimento da prisão. Petrópolis, RJ: Vozes, 9ª ed.: 1987. Versão original: Surveiller et Punir. Paris: Gallimard.

. (1976). História da Sexualidade I: A vontade de saber. Rio de Janeiro: Edições Graal, 1ª ed.: 1988; 11ª ed.:1993. Edição original: Histoire de la Sexualité I - La Volonté de savoir.

FREIRE, P. (1973). Pedagogia del Oprimido. Buenos Aires: Argentina Editores. 
GENTILI, P. A. A. (1994). O discurso da "qualidade" como nova retórica conservadora no campo educacional. Em: Gentili, P.A.A. \& Silva, T.T. (orgs.) Neoliberalismo, Qualidade Total e Educação - Visões Críticas. Petrópolis, RJ: Vozes: p. 111-178.

LARROSA, J. (1994). Tecnologias do Eu e Educação. Em: Silva, T.T. (org.). O Sujeito da Educação - Estudos Foucaultianos. Petrópolis, RJ.: Editora Vozes: p. 35-86.

LIMA, A. O. (1994). Avaliação Escolar - Julgamento x Construção. Petrópolis, R.J.: Vozes.

MOREIRA, A.F. (1995). O Currículo como Política Cultural e a Formação Docente. Em: Silva, T.T. \& Moreira, A.F. Territórios Contestados- O Currículo e os Novos Mapas Políticos e Culturais. Petrópolis, RJ: Vozes: p. 7-20.

ORLANDI, E. P. (1986). A Linguagem e seu Funcionamento: As formas do discurso. Campinas, SP: Pontes.

ORLANDI, E.P. \& GUIMARÃES, E. (1988). Unidade e Dispersão: Uma Questão do Texto e do Sujeito. Sujeito e Texto, Série Cadernos PUC (31). São Paulo: EDUC:p. 17-36.

PIGNATELli, F. (1994). Que Posso Fazer? Foucault e a Questão da Liberdade e da Agência Docente. Em: Silva, T.T. (org.). O Sujeito da Educação - Estudos Foucaultianos. Petrópolis, RJ.: Editora Vozes: p. 127-154. 